Ife Journal of Science vol. 20, no. 3 (2018)

\title{
PREVALENCE AND ANTIMICROBIAL RESISTANCE OF PSEUDOMONAS AERUGINOSA RECOVERED FROM ENVIRONMENTAL AND CLINICAL SOURCES IN BENIN CITY, NIGERIA
}

\author{
Isichei-Ukah, O. B. ${ }^{*}$ and Enabulele, O. I. \\ Department of Microbiology, Faculty of Life Sciences, University of Benin, PMB 1154, Benin City, Nigeria \\ "Corresponding author's email: brenda.isichei@uniben.edu \\ (Received: $10^{\text {th }}$ January, 2018; Accepted: $13^{\text {th }}$ September, 2018)
}

\section{ABSTRACT}

\begin{abstract}
The increasing rate of resistance to antimicrobial agents is a public health challenge and Psendomonas aeruginosa is known to have recalcitrant resistance to several antibiotics. In this study, we characterized antimicrobial resistance and multiple antibiotic resistance (MAR) index of $P$. aeruginosa of environmental and clinical origin. A total of 240 samples were examined, of which 120 each were of environmental and clinical settings. Bacteriological analysis, antimicrobial sensitivity and MAR were performed on the isolates. The results revealed that of the 120 clinical matrixes evaluated for the presence of $P$. aeruginosa, 54.16\% (65/120) were positive for $P$. aeruginosa. There were significant differences among the clinical samples $(p<0.05)$ in prevalence. The highest isolation rate $27.7 \%$ was observed in wound samples and the least $10.8 \%$ in urine. For environmental samples, $45.83 \%$ (55/120) were positive for $P$. aeruginosa. There was a highly significant difference among the environmental samples $(p<0.01)$ in prevalence. All positive isolates were resistant to cefuroxime $(100 \%)$ and amoxicillin $(100 \%)$. Most were also resistant to nalidixic acid (88\%), cotrimoxazole $(86 \%)$ and ciprofloxacin $(85 \%)$. There was high significant difference in the resistance patterns of the isolates at $p<0.001$. All the isolates were multi-resistant revealed by the high MAR index profile. The multi-resistance exhibited by $P$. aeruginosa further confirms the call for integrated approaches to combat bacterial antibiotic resistance.
\end{abstract}

Keywords: Pseudomonas aeruginosa, Antibiotics resistance, Multidrug resistance

\section{INTRODUCTION}

Pseudomonads are non-fermentative, aerobic, Gram-negative bacilli that are ubiquitous in water, soil, and other humid environs. Pseudomonas aeruginosa is frequently ascribed with ailments in humans, where it functions as nosocomial microbial pathogen with a functional systematic approach to initiate infections in virtually any tissue or organ, particularly in immunocompromised patients or in elderly individuals. The ability of $P$. aeruginosa to initiate diseases is increased by both acquired and innate resistance to a significant number of disinfectants and antimicrobials, ability to strive in a broad range of environmental conditions and virulence determinants (Kerr and Snelling, 2009).

Pseudomonas aeruginosa thrives not only in normal atmospheres, but also in low-oxygen atmospheres, thus has colonized many natural and artificial environments. It uses a wide range of organic material for food; in animals, its versatility enables the organism to infect damaged tissues or those with reduced immunity. In healthcare settings, the bacterium is regarded as a potent cause of infection in individuals with diverse vulnerability including those receiving intensive care or with burns or neutropenia, bacteremia, wound infections as well as other superficial and systemic infections (Lodise et al., 2007). Amongst these categories of persons, morbidity and mortality attributable to infection of $P$. aeruginosa origin can be on the rise. Managing these ailments could prove difficult as $P$. aeruginosa is adversely resistant to broad numbers of antimicrobials. In addition, treatment regimen has become difficult due to emergence and spread of resistant strains of the organism (Kollef et al., 2008).

Literature have reported a number of outbreaks of $P$. aeruginosa affecting intensive care units (ICUs) which have established the potential for Pseudomonas spp., to institute microbial reservoirs in the healthcare environment (Hota et al., 2009; Breathnach et al., 2012). In contrast with other environmental pathogens of public health importance, $P$. aeruginosa flourishes in the environment over an extensive range of temperatures with an overwhelming capacity at manipulating and flourishing in relatively nutrientpoor surroundings (Igbinosa and Obuekwe, 2014). Its capsular polysaccharide facilitates it to 
stick to surfaces. Contrariwise, when good environmental conditions prevail, the cells embark on the exponential phase rapidly on surfaces in connection with water carriage systems to form biofilms (Loveday et al., 2014).

A notable advancement is carbapenemasesproducing ability by some strains of $P$. aeruginosa origin. As a consequence of these challenges, it would seem reasonable to identify sources and reservoirs of this bacterium so as to prevent the acquisition of the bacterium by both hospitalized and un-hospitalized persons. Numerous reports of ailments from $P$. aeruginosa outbreaks have been attributed to environmental sources (Jefferies et al., 2012). However, the routes of such sources in sporadic pseudomonad ailments are well less understood. Nonetheless, there is evolving substantiation from potential studies to suggest that environmental sources may have significance in the epidemiology of sporadic $P$. aeruginosa infections in clinical settings. A better understanding of the antimicrobial resistance profiling of clinical and environmental reservoirs in pseudomonads isolates will permit the development of new strategies and refinement of existing approaches to interrupt transmission from these sources. Hence, this study was aimed at determining the antibiogram profiling of Pseudomonas aeruginosa from clinical and environmental sources.

\section{MATERIALS AND METHODS Collection of Samples}

A total of 240 specimens comprising 120 each from clinical and environmental sources were examined. The samples were collected from two government-owned hospitals (University of Benin Teaching Hospital and Central Hospital, Benin); and two privately-owned hospitals (St. Philomena Catholic Hospital, Benin and Faith Mediplex, Benin), in Benin City, Edo State, Nigeria.

The clinical samples were made up of 20 urine samples, sputum, 20 wound swab samples, 20 blood samples, 20 infected ear swab samples and 20 swab samples from the eyes. They were collected from hospitalized and non-hospitalized persons attending the clinics. Ethical clearance was obtained for the collection of clinical samples.
The environmental samples were from hospital environment (80), abattoirs (20) and dump sites (20) within Benin City. All samples were collected aseptically.

\section{Isolation of Pseudomonas aeruginosa}

An aliquot of $1.0 \mathrm{ml}$ of the samples was serially diluted using standardized serial dilution procedures to the order of $10^{6}$. Thereafter, $100 \mu \mathrm{l}$ from respective diluent $\left(10^{2}-10^{6}\right)$ were inoculated on cetrimide agar and incubated at $37^{\circ} \mathrm{C}$ for $18-24$ h. Discrete green colonies on the cetrimide agar were sub-cultured and purified on cetrimide agar and incubated at $37{ }^{\circ} \mathrm{C}$ for $18-24 \mathrm{~h}$. Thereafter, colonies were purified on nutrient agar and incubated at $37^{\circ} \mathrm{C}$ for $24-48 \mathrm{~h}$, and stored using agar slants at $4{ }^{\circ} \mathrm{C}$ until ready for use in subsequent analysis.

\section{Phenotypic Identification of Pseudomonas aeruginosa}

The presumptive identified Pseudomonas aeruginosa isolates were further subjected to haemolysis on blood agar, catalase, urease, indole, Gram reaction, citrate, oxidase, oxidation/fermentation reaction, and motility test as described by Cheesbrough (2005).

\section{Antibiotic Susceptibility Testing}

Antibiotics susceptibility testing was carried out using the disc diffusion (Kirby-Bauer) technique, as recommended by standard guidelines of the Clinical and Laboratory Standards Institute (CLSI, 2014). Briefly, a single inoculum of each bacterial isolates was emulsified in $5.0 \mathrm{ml}$ sterile normal saline in Bijou bottles to make a lawn of bacteria. Sterile cotton swabs were dipped into the standardized solution of bacterial cultures and used to inoculate Mueller-Hinton agar plates. Thereafter, antibiotic discs (Mast Diagnostics, Merseyside, United Kingdom) containing the antibiotics: amikacin $(30 \mu \mathrm{g})$, gentamicin $(10 \mu \mathrm{g})$, streptomycin $(10 \mu \mathrm{g})$, tobramycin $(10 \mu \mathrm{g})$, ceftazidime $(30 \mu \mathrm{g})$, ceftriaxone $(30 \mu \mathrm{g})$, cefuroxime $(30 \mu \mathrm{g})$, amoxicillin $(10 \mu \mathrm{g})$, imipenem $(10 \mu \mathrm{g})$, meropenem $(10 \mu \mathrm{g})$, cotrimoxazole $(25$ $\mu \mathrm{g})$, aztreonam $(30 \mu \mathrm{g})$, chloramphenicol $(30 \mu \mathrm{g})$, ciprofloxacin $(5 \mu \mathrm{g})$, ofloxacin $(5 \mu \mathrm{g})$, nalidixic acid $(30 \mu \mathrm{g})$ and tetracycline $(30 \mu \mathrm{g})$, were placed on the plates. Discs were placed at least $15 \mathrm{~mm}$ apart and from the edges of the plates to prevent 
overlapping of inhibition zones. The plates were incubated at $37^{\circ} \mathrm{C}$ for $18-24 \mathrm{~h}$, after which zones of inhibition (millimetres) were measured to determine sensitivity, intermediate or resistance profile. The zones were interpreted according to the standards of Clinical and Laboratory Standards Institute (CLSI, 2014).

Multiple Antibiotic Resistances (MAR) Index The multiple antibiotic resistance (MAR) index was determined for each isolate by dividing the number of antibiotics to which the isolate is resistant by the total number of antibiotics tested (Krumpernam, 1983).

MAR index $=\frac{\text { Number of antibiotics isolate is resistant to }}{\text { Total number of antibiotics tested }}$

MAR index higher than 0.2 identifies that organism to have originated from high-risk sources of contamination, where antibiotics are often used (Krumpernam, 1983).

\section{Statistical Analysis}

All data were tabulated and analyzed using SPSS, version 12.0. Qualitative variables were expressed by percentages and compared using charts and chi-square test. A $p$-value $<0.05$ was considered statistically significant.

\section{RESULTS}

A total of 120 clinical matrixes evaluated for the presence of $P$. aeruginosa, $54.16 \%(65 / 120)$ were positive for $P$. aeruginosa. There were significant differences among the clinical samples $(\phi<0.05)$ in prevalence. The highest isolation rate $27.7 \%$ was observed in wound samples and the least $10.8 \%$ in urine (Table 1). The 120 environmental samples evaluated revealed that $45.83 \%(55 / 120)$ were positive for $P$. aeruginosa. There was a highly significant difference among the environmental samples $(\phi<0.01)$ in prevalence (Table 2$)$.

Table 1: Prevalence of P. aeruginosa from Clinical Samples

\begin{tabular}{lll}
\hline Clinical Specimens & $\begin{array}{c}\text { Total no of } \\
\text { Samples }\end{array}$ & Positive Samples for P. aeruginosa \\
\hline Sputum & 20 & $9(13.8)$ \\
Wound & 20 & $18(27.7)$ \\
Urine & 20 & $7(10.8)$ \\
Blood & 20 & $10(15.4)$ \\
Ear & 20 & $13(20.0)$ \\
Eyes & 20 & $8(12.3)$ \\
Total & 120 & $65(100)$ \\
\hline
\end{tabular}

$\mathrm{p}<0.05$

Table 2: Prevalence of P. aeruginosa from Environmental Sources

\begin{tabular}{lll}
\hline Environmental Sites & $\begin{array}{l}\text { Total no of } \\
\text { Samples }\end{array}$ & Positive Samples for P. aeruginosa \\
\hline Abattoir & 20 & $9(16.4)$ \\
Dump sites & 20 & $16(29.1)$ \\
Catheter tips & 20 & $11(20.0)$ \\
Hospital walls & 20 & $6(10.9)$ \\
Hospital beds & 20 & $5(9.1)$ \\
Hospital sinks & 20 & $8(14.5)$ \\
Total & 120 & $55(100)$ \\
\hline $\mathrm{p}<0.01$ &
\end{tabular}


The antibiotic susceptibility patterns of clinical and environmental isolates are shown in table 3. All positive clinical isolates were resistant to cefuroxime $(100 \%)$ and amoxicillin (100\%). Most of the clinical isolates were also resistant to nalidixic acid (88\%), cotrimoxazole $(86 \%)$ and ciprofloxacin $(85 \%)$. There was a very high significant difference in the resistance patterns amongst the clinical isolates at $p<0.001$. The clinical isolates were most sensitive to imipenem $(91 \%)$, amikacin $(78 \%)$, ceftazidime $(75 \%)$ and meropenem $(72 \%)$ (Table 3).

All environmental isolates were resistant to cefuroxime $(100 \%)$, amoxicillin $(100 \%)$, tetracycline $(100 \%)$ and chloramphenicol (95\%). There was a very high significant difference in the resistance patterns of the environmental isolates at $p<0.001$. Some of the environmental isolates were however sensitive to ceftazidime (78\%), meropenem (77\%), amikacin $(73 \%)$ and imipenem (71\%) (Table 3).

Table 3: Antibiotic Susceptibility of P. aeruginosa Isolates from Clinical and Environmental Sources

\begin{tabular}{l|l|lll|lll}
\hline \multirow{2}{*}{$\begin{array}{l}\text { Antibiotic } \\
\text { Class }\end{array}$} & Antibiotics & \multicolumn{3}{l|}{ Clinical $(n=65)$} & & \multicolumn{3}{l}{ Environmental $(n=55)$} \\
\cline { 3 - 7 } & & $\mathrm{R}(\%)$ & $\mathrm{I}(\%)$ & $\mathrm{S}(\%)$ & $\mathrm{R}(\%)$ & $\mathrm{I}(\%)$ & $\mathrm{S}(\%)$ \\
\hline Aminoglycosides & Amikacin (AK) & $13(20)$ & $1(2)$ & $51(78)$ & $14(25)$ & $1(2)$ & $40(73)$ \\
& Gentamicin (GM) & $46(71)$ & $8(12)$ & $11(17)$ & $24(44)$ & $11(20)$ & $20(36)$ \\
& Streptomycin (S) & $40(62)$ & $10(15)$ & $15(23)$ & $44(80)$ & $11(20)$ & $0(0)$ \\
& Tobramycin (TN) & $51(78)$ & $8(12)$ & $6(15)$ & $35(64)$ & $13(23)$ & $7(13)$ \\
Cephalosporines & Ceftazidime (CAZ) & $13(20)$ & $3(5)$ & $49(75)$ & $10(18)$ & $2(4)$ & $43(78)$ \\
& Ceftriaxone (CRO) & $31(48)$ & $25(38)$ & $9(14)$ & $31(56)$ & $16(29)$ & $8(15)$ \\
Penicillins & Cefuroxime (CXM) & $65(100)$ & $0(0)$ & $0(0)$ & $55(100)$ & $0(0)$ & $0(0)$ \\
Carbapenems & Amoxicillin (A) & $65(100)$ & $0(0)$ & $0(0)$ & $55(100)$ & $0(0)$ & $0(0)$ \\
& Imipenem (IMI) & $4(6)$ & $2(3)$ & $59(91)$ & $10(18)$ & $6(11)$ & $38(71)$ \\
Follate Inhibitors & Meropenem (MEM) & $15(23)$ & $3(5)$ & $47(72)$ & $10(18)$ & $3(5)$ & $42(77)$ \\
Monobactams & Cotrimoxazole (TS) & $56(86)$ & $3(5)$ & $6(9)$ & $48(87)$ & $2(4)$ & $5(9)$ \\
Phenicols & Aztreonam (ATM) & $44(68)$ & $9(14)$ & $12(18)$ & $46(84)$ & $4(7)$ & $5(9)$ \\
Quinolones & Chloramphenicol (C) & $34(52)$ & $15(23)$ & $16(25)$ & $52(95)$ & $3(5)$ & $0(0)$ \\
& Ciprofloxacin (CIP) & $55(85)$ & $4(6)$ & $6(9)$ & $35(64)$ & $7(13)$ & $13(23)$ \\
& Ofloxacin (OFX) & $44(68)$ & $11(17)$ & $10(15)$ & $34(62)$ & $5(9)$ & $16(29)$ \\
Tetracyclines & Nalidixic acid (NA) & $57(88)$ & $4(6)$ & $4(6)$ & $49(89)$ & $4(7)$ & $2(4)$ \\
\hline
\end{tabular}

Legend: \% S- Sensitivity rate; \% I- Intermediate rate; \% R- Resistance rate

The resistant percentage profile of $P$. aeruginosa of the clinical and environmental isolates to each of the antibiotics tested is shown in figure 1 . There was no significant difference in resistance pattern between the clinical and environmental isolates to the following antibiotics: amikacin, streptomycin, tobramycin, ceftazidime, ceftriaxone, cefuroxime, amoxicillin, meropenem, cotrimoxazole, aztreonam, ciprofloxacin, ofloxacin and nalidixic acid, $(p>0.05)$. There was high significant difference in resistance pattern to gentamicin, imipenem, chloramphenicol and tetracycline at $p<0.01$ significance level.

The multiple antibiotic resistance (MAR) indices of the evaluated clinical and environmental isolates are shown in figure 2. Isolates from blood, wound, catheter and dump sites revealed very high MAR index values $(>0.8)$, indicating high-risk sources of contamination and possible transmission of infection. 


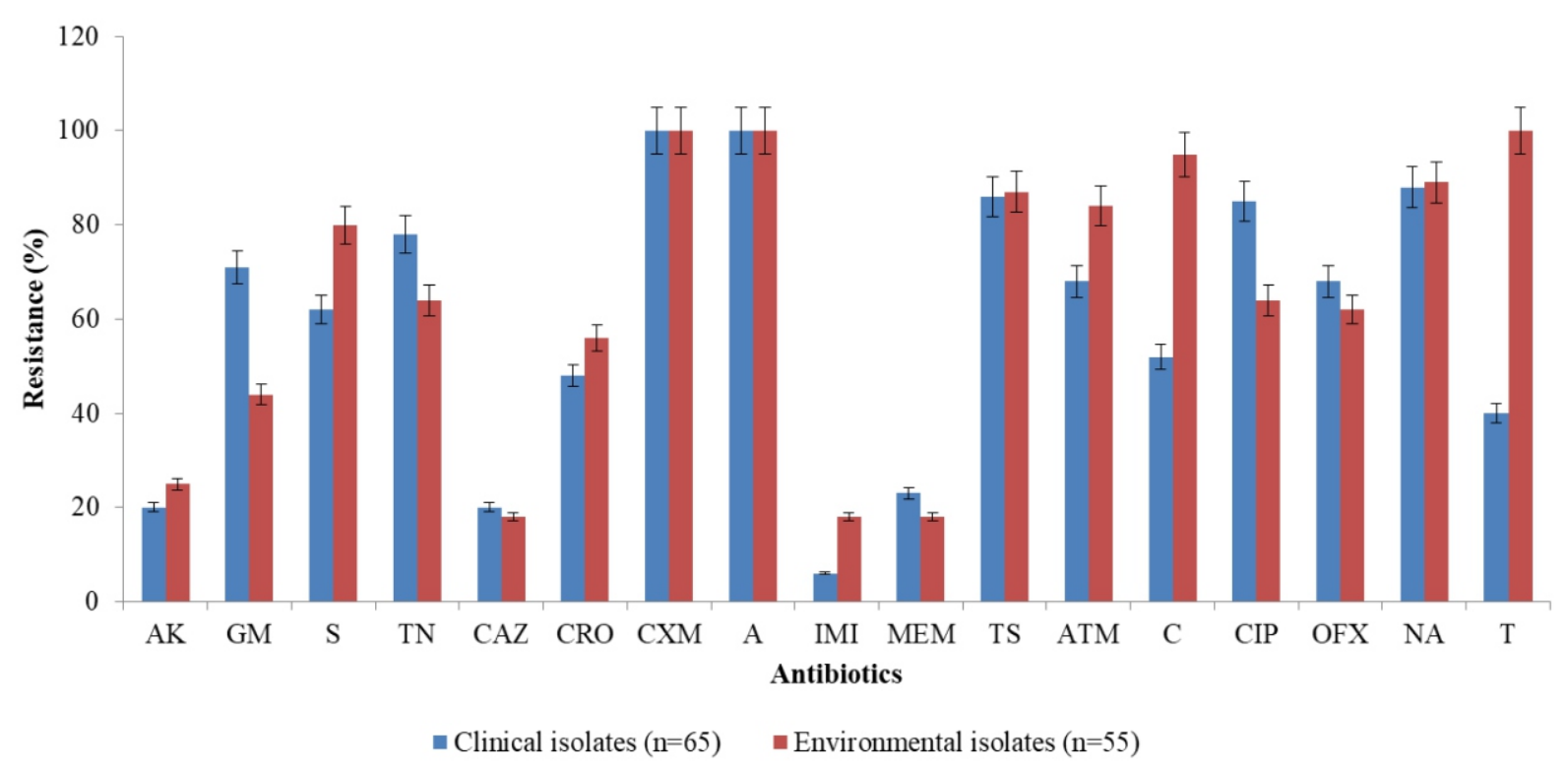

Figure 1: Percentage Profile of $P$. aeruginosa Resistant from Clinical and Environmental Isolates

Legend: $A K=$ Amikacin, $G M=$ Gentamicin,$S=$ Streptomycin, $T N=$ Tobramycin, $C A Z=C e f t a z i d i m e$, $\mathrm{CRO}=$ Ceftriaxone, $\mathrm{CXM}=$ Cefuroxime, $\mathrm{A}=$ Amoxicillin, $\mathrm{IMI}=$ Imipenem, $\mathrm{MEM}=$ Meropenem, TS=Cotrimoxazole, ATM=Aztreonam, $\mathrm{C}=$ Chloramphenicol, $\mathrm{CIP}=$ Ciprofloxacin, $\mathrm{OFX}=$ Ofloxacin, $\mathrm{NA}=$ Nalidixic acid, $\mathrm{T}=$ Tetracycline.

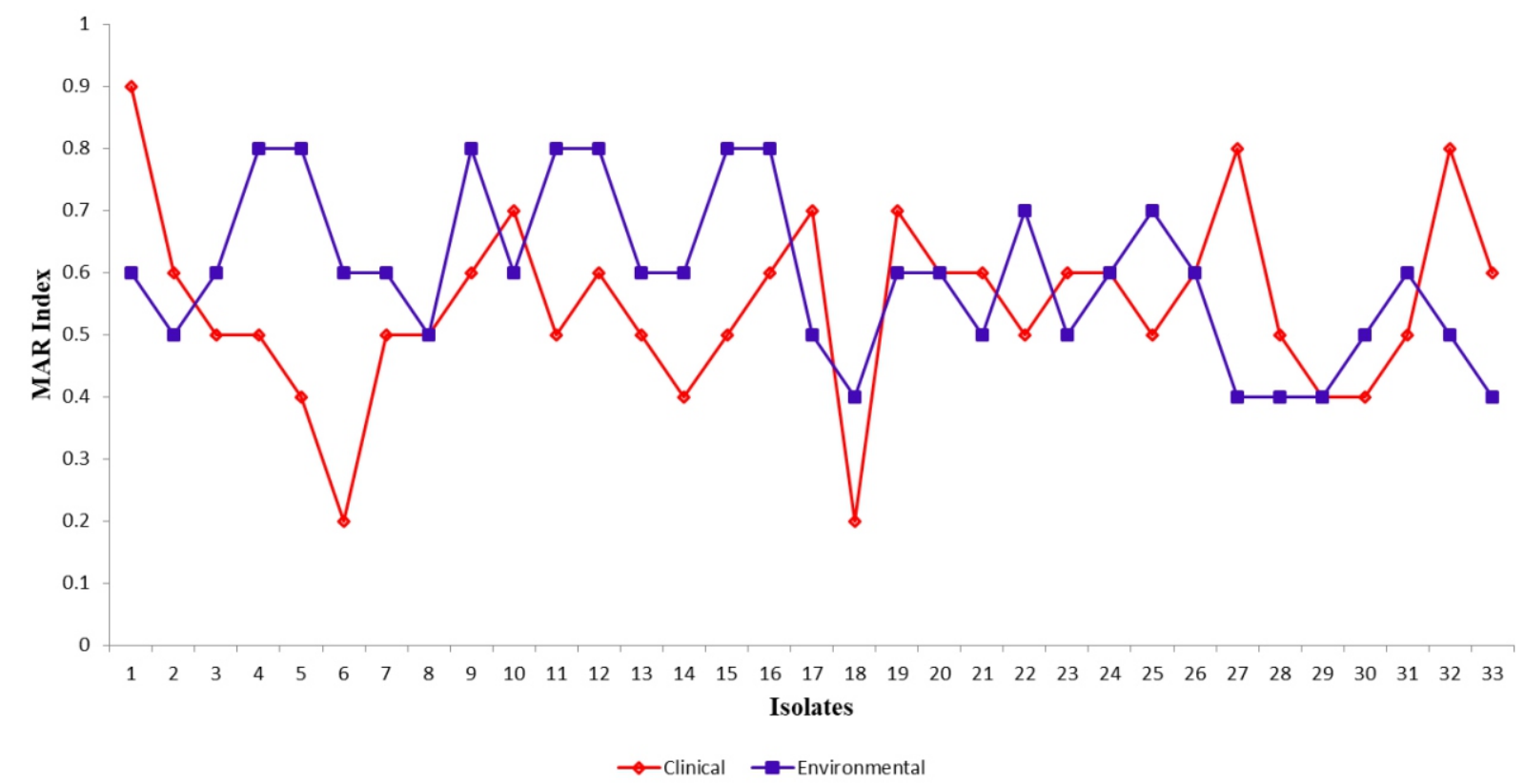

Figure 2: Multiple Antibiotic Resistance (MAR) Index Profile from Clinical and Environmental Isolates of Pseudomonas aeruginosa

\section{DISCUSSION}

Pseudomonas aeruginosa remains a significant nosocomial pathogen associated with morbidity and mortality, particularly for immunocompromised individuals and vulnerable patients on intensive care units (Kerr and Snelling, 2009). Findings from this study have stressed the important potential clinical (sputum, wound/burns, urine, blood, ear and eyes infection) and environmental sources (abattoir, dumpsites, catheter tips, hospital walls, hospital beds and hospital sinks) as a potential reservoir of antibiotic-resistant $P$. aeruginosa. 
Earlier reports in Nigeria showed varying isolation rates of this organism from clinical samples. These include those of Odusanya (2002) who reported $4.6 \%$ for urine and $16.3 \%$ from wound infections, prevalence of $11.1 \%$ in open musculoskeletal injuries (Akinyola and Ako-Nai, 2005); $41.9 \%$ and $39.35 \%$ from ear and wound swab respectively (Ogbolu et al., 2008). From this study also, the highest isolation rate of $90 \%$ was observed in wound samples and the least $35 \%$ in urine $(P>0.05)$. This represents a major public health hazard for both hospital and community acquired infection especially for surgical wound contamination.

From the environmental samples, the results indicated that $45.80 \%$ were positive for $P$. aeruginosa. The prevalence of the organism in clinical specimens $(54.2 \%)$ was not significantly different $(P>0.05)$ from that of environmental specimens $(45.80 \%)$. High prevalence was observed in dumpsites (80\%) and catheter tips $(55 \%)$. The organism had been isolated from catheter tip (Aibinu et al., 2007; and Mansour et al., 2013). Previous reports of isolation from dump sites include the works of Achudume and Olawale (2007), and Oviasogie et al., (2010). The high prevalence of the organism in dumpsites in this study is a potential threat to health in the case of indiscriminate dumping of wastes. The organism was also isolated from abattoirs, which is in agreement with a study conducted by Igbinosa and Obuekwe (2014) on abattoir environment around Benin City.

As regards hospital environment, the range of reservoirs in healthcare environments from which $P$. aeruginosa has been isolated is wide ranging from potable water, tap traps, showers, disinfectants, respiratory therapy equipment, mop heads, endoscopes, urometers, water baths, hydrotherapy pools, infant feeding basins, bathing basins, bath toys to cleaning equipment (Rogues et al., 2007). Several properties of $P$. aeruginosa contribute to persistence in the hospital environment. The organism is inherently resistant to several disinfectants such as biguanides and quaternary ammonium compounds through the mechanism of multidrug efflux pumps. Also, the ability of the organism to form biofilm on inanimate surfaces also favours disinfectant resistance as well as impeding physical removal. The type III secretion system to kill free-living amoeba which graze on environmental bacteria also contributes to its persistence in moist environments (Matz et al., 2008).

In this study, a good percentage of the clinical and environmental isolates were resistant to majority of the antibiotics: penicillins (100\%), the cephalosporins: ceftriaxone and cefuroxime (48\% - 100\%) and sulphamethoxazole (86\% - 87\%) in agreement with reports of other authors ( $\mathrm{Li}$ et al., 2010; and Ashish et al., 2011). The data showed the highest antibiotic resistance to amoxycilin and cefuroxime, and the lowest resistance to imipenem, meropenem, amikacin and ceftazidime, in both clinical and environmental isolates. This correlated with the works of Mahmoud et al. (2013) who reported from their research that amikacin and imipenem were the most effective drugs against $P$. aeruginosa. Haleem et al. (2011) also reported that clinical and environmental isolates of $P$. aeruginosa was $100 \%$ resistance to cefotaxime, chloramphenicol, penicillin, ampicillin, doxycycline, erythromycin, tetracycline and cloxacillin. High resistances of these isolates to the $\beta$ - lactam antibiotics may be due to production of beta-lactamase enzymes that breakdown the beta-lactam ring. Pirnay et al. (2005) reported that Pseudomonas species were naturally resistant to the penicillins, cephems and rifampin because they have relatively impermeable membrane, inducible efflux systems and a chromosomally encoded inducible $\beta$-lactamase.

The resistance rate to imipenem was $6 \%$ and $18 \%$, clinical and environmental isolates respectively. A decline in the resistance to imipenem could be attributed to the restricted use of this antibiotic. The result of this study showed that there is marked increase in resistance to the quinolones (ciprofloxacin, ofloxacin and nalidixic acid). Nalidixic acid had the highest resistance $(88 \%$ and $89 \%$ ) and was closely followed by ciprofloxacin (85\% and 64\%) and ofloxacin (68\% and 62\%) for clinical and environmental isolates respectively. This result implies that quinolones alone cannot be depended upon as an antipseudomonal antimicrobial in this environment. In previous studies by Aibinu et al. (2007), Pseudomonas aeruginosa strains were found to be highly 
susceptible to the quinolones $(96 \%)$. Due to the increasing resistance to nalidixic acid in many hospitals, its empirical usage is either banned or restricted, to bring the developing resistance rates under control (Algun et al., 2004).

It was interesting to note that all the environmental isolates were resistant to tetracycline. The remarkable multi-resistances to tetracycline could be that this antibiotic is highly misused because of constant and indiscriminate usage in our environment (), and an intrinsic and acquired resistance mechanism caused mainly by an active efflux system, which efficiently expels the compound from the cell ( ). The resistance observed in $P$. aeruginosa to a number of antibiotics could be as a result of gene transfer into the hospital environment, which is a common nosocomial occurrence and incessant use of antibiotics. From this study, there was no significant difference between resistance patterns of clinical and environmental isolates $(\mathrm{P}>0.05)$ to majority of the antibiotics.

All the tested isolates in this study showed multiple antibiotic resistances (MARs) ranging from four to 16 antibiotics distributed among three to seven classes. The MAR indices were higher than the 0.2 limit in almost all tested isolates. This correlates with studies of Odjadjare et al. (2012) who reported MAR of five to 11 antibiotics. NavonVenezia et al. (2005) observed that MAR bacterial strains may also arise as a result of unrelated mechanisms accumulating sequentially in an organism. The observation indicates that isolates in this study originated from high risks source(s) of contamination. Multi-drug resistance in environmental isolates might be linked to the uncontrolled disposal of antibiotics and chemicals into the environment creating a selective pressure on these drugs. The use of antibiotics in hospital and the community at large serves as a major selective pressure for antibiotic resistant bacteria ( ) .

\section{CONCLUSION}

This study has established that $P$. aeruginosa is highly ubiquitous and can be isolated from diverse clinical and environmental sources at different ecological habitat. The isolates were resistant to majority of the anti-pseudomonad drugs tested, and sources originated from high risk sources of contamination. The diversity and prevalence of resistance phenotypes in clinical and environmental sources inspire hypotheses about the native roles of resistance gene element in natural microbial communities.

\section{REFERENCES}

Achudume, A.C. and Olawale, J.T. (2007). Microbial pathogens of public health significance in waste dumps and common sites. Journal of Environmental Biology, 28(1):151-154.

Aibinu, I., Nwanneka, T., Odugbemi, T. (2007). Occurrence of ESBL and MBL in clinical isolates of Pseudomonas aeruginosa from Lagos, Nigeria. Journal of American Science, 3(4):81-85.

Akinyola, A.L. and Ako-Nai, A.K. (2005). Microbial isolates in early swabs of musculoskeletal injuries. West African Journal of Medicine, 24(3):273-278.

Akoachere, J.T.K., Ndip, R.N., Chenwi, E.B, Ndip, L.M, Njock, T.E., Anong, D.N. (2002). Antibacterial effect of Zinziber officinale and Garcinia kola on respiratory tract pathogens. East African Medical Journal, 79:588-591.

Algun, A., Arisoy, A., Gunduz, T., Ozbakkaloglu, B. (2004). The resistance of Pseudomonas aeruginosa strains to fluoroquinolone group of antibiotics. Indian Journal of MedicalMicrobiology, 22(2):112-114.

Ashish, J., Warghane, G.N., Wagh, B.B., Nag, S.P., Jisnani, M.L., Thaware, R.R., Kitey, H.S. (2011). Isolation and characterization of Pseudomonas species from Godavari river sample. Asian Journal Biotechology, 2:862-866.

Breathnach, A.S., Cubbon, M.D., Karunaharan, R.N., Pope, C.F., Planche, T.D. (2012). Multidrug-resistant Pseudomonas aeruginosa outbreaks in two hospitals: association with contaminated hospital waste-water systems., 82(1):19-24.

Cheesbrough, M. (2005). District Laboratory Practice for Tropical Countries, part 2. Cambridge University Press, UK, 429 pp.

Clinical Laboratory Standards Institutes [CLSI] (2014). Performance Standards for 
Antimicrobial Susceptibility Testing. TwentyFourth Informational Supplement (Document M100-S24) 34 (1) 230pp.

Haleem, H., Tarrad, J. K., Banyan, I. A. (2011). Isolation of Pseudomonas aeruginosa from clinical cases and environmental samples and analysis of its antibiotic resistant spectrum at Hilla Teaching Hospital. Medical Journal of Babylon, 8:618-624.

Hota, S., Hirji, Z., Stockton, K., Lemieux, C., Dedier, H., Wolfaardt, G., Gardam, M. A. (2009). Outbreak of multidrug-resistant Pseudomonas aeruginosa colonization and infection secondary to imperfect intensive care unit room design. Infection Control and HospitalEpidemiology, 30(1):25-33.

Igbinosa, E.O. and Obuekwe, I.S. (2014). Evaluation of antibiotic resistant gene in abattoir environment. Journal of Applied Science and Environmental Management, 18(2):165-170.

Jefferies, J.M.C., Cooper, T., Yam, T., Clarke, S.C. (2012). Pseudomonas aeruginosa outbreaks in the neonatal intensive care unit - a systematic review of risk factors and environmental sources. Journal of Medical Microbiology, 61:1052-1061.

Kerr, K.G. and Snelling, A.M. (2009). Pseudomonas aeruginosa: a formidable and ever-present adversary. Journal of Hospital Infection, 73:338-344.

Kohler, T., Delden, C.V., Curty, L.K., Hamrehpour, M.M., Pechere, J.C. (2001). Over expression of the MexEF-OprN multi-drug efflux system affects cell-tocell signalling in Pseudomonas aeruginosa. Journal of Bacteriology, 183:5213-5222.

Kollef, K.E., Schramm, G.E., Wills, A.R., Reichley, R.M., Micek, S.T., Kollef, M.H. (2008). Predictors of 30-day mortality and hospital costs in patients with ventilatorassociated pneumonia attributed to potentially antibiotic-resistant Gramnegative bacteria. Chest 134: 281-287.

Krumperman, P.H. (1983). Multiple antibiotic resistance indexing of Escherichia coli to identify high-risk sources of fecal contamination of foods. Applied and EnvironmentalMicrobiology, 46:165-170.

Li, D., Yu, T., Zhang, Y., Yang, M., Li, Z., Liu, M., Qi, R. (2010). Antibiotic resistance characteristics of environmental bacteria from an oxytetracycline production wastewater treatment plant and the receiving river. Applied and Environmental Microbiology, 76:3444-3451.

Lodise Jr, T.P., Patel, N., Kwa, A. (2007). Predictors of 30-day mortality among patients with Pseudomonas aeruginosa bloodstream infections: impact of delayed appropriate antibiotic selection. Antimicrobial Agents and Chemotherapy, 51:3510-3515.

Loveday, H.P., Wilson, J.A., Kerr, K., Pitchers, R., Walker, J.T., Browne, J. (2014). Association between healthcare water systems and Pseudomonas aeruginosa infections: a rapid systematic review. Journal of Hospital Infection, 86: 7-15.

Mahmoud, A.B., Zahran, W.A., Hindawi, G.R., Labib, A.Z., Galal, R. (2013). Prevalence of multidrug-resistant Psendomonas aeruginosa in patients with nosocomial infections at a University Hospital in Egypt, with special reference to typing methods. Journal of Virology and Microbiology 1:1-13.

Mansour, S.A., Eldaly, O., Jiman-Fatani, A., Mohamed, M.L., Ibrahim, E.M. (2013). Epidemiological characterization of $P$. aeruginosa isolates of intensive care units in Egypt and Saudi Arabia. Eastern Mediterranean Health Journal, 19(1):71-80.

Matz, C., Moreno, A.M., Alhede, M. (2008). Pseudomonas aeruginosa uses type III secretion system to kill biofilm-associated amoebae. The ISME Journal, 2:843-852.

Moreira, B.M., Pellegrino, F.L.P.C., Teixeira, L.M. (2002). Occurrence of multi-drugresistance Pseudomonas aeruginosa clone in different hospitals in Rio de Janeiro, Brazil. Journal of Clinical Microbiology, 40:2420-2424.

Navon-Venezia, S., Ben-Ami, R., Carmeli, Y. (2005). Update on Pseudomonas aeruginosa and Acinetobacter baumannii infections in the healthcare setting. Current Opinion on Infectious Diseases, 18(4):306-313.

Odjadjare E.E., Igbinosa, E.O., Mordi, R., Igere, 
B., Igeleke, C.L., Okoh, A.I. (2012). Prevalence of Multiple Antibiotics Resistant (MAR) Pseudomonas species in the final effluents of three municipal wastewater treatment facilities in South Africa. International Journal of Environmental Research and Public Health, 9:2092-2107.

Odusanya, O.O. (2002). Antibiotic susceptibility of microorganisms at a General Hospital in Lagos, Nigeria. Journal of the National Medical Association, 94:994-998.

Ogbolu, D.O., Ogunledun, A., Adebiyi, D.E., Daini, O.A., Terry, A.O. (2008). Antibiotic sensitivity pattern of Pseudomonas aeruginosa to available anti-pseudomonal drugs in Ibadan, Nigeria. African Journal of Medicine and Medical Sciences, 37(3):339-344.
Oviasogie, F.E., Ajuzie, C.U. and Ighodaro, U.G. (2010). Bacterial analysis of soil from waste dumpsite. Archives of Applied Science Research, 2(5):161-167.

Pirnay, J.P., Matthijs, S., Colak, H., Chablain, P., Bilocq, F., van Eldere, J., de Vos, D., Zizi, M., Triest, L., Cornelis, P. (2005). Global Psendomonas aeruginosa biodiversity as reflected in a Belgian river. Environmental Microbiology, 7:969-980.

Rogues, A.M., Boulestreau, H., Lasheras, A., Boyer, A., Gruson, D., Merle, C., Castaing, Y., Bebear, C. M., Gachie, J. P. (2007). Contribution of tap water to patient colonisation with Pseudomonas aeruginosa in a medical intensive care unit. Journal of Hospital Infection, 67:72-78. 